\title{
Climate change adaptation and regional forest planning in southern Yukon, Canada
}

\author{
A. E. Ogden • J. L. Innes \\ Published online: 19 June 2008 \\ (C) Springer Science + Business Media B.V. 2008

\section{Erratum to: Mitig Adapt Strateg Glob Change DOI 10.1007/s11027-008-9144-7}

Figure 2 has been updated because of a typographical error - drier winters should read drier summers.

The online version of the original article can be found at http://dx.doi.org/10.1007/s11027-008-9144-7

\footnotetext{
A. E. Ogden $\cdot$ J. L. Innes

Sustainable Forest Management Laboratory, Department of Forest Resources Management, Faculty of Forestry, University of British Columbia, Vancouver, Canada

J. L. Innes

e-mail: john.innes@ubc.ca

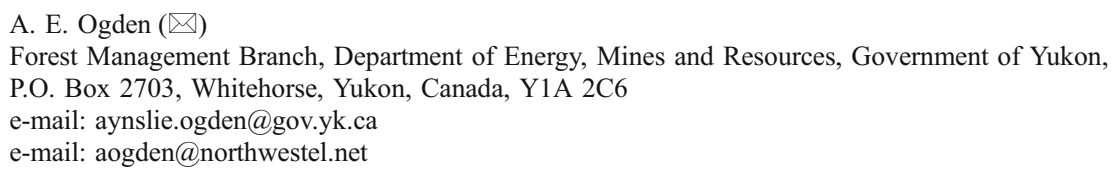




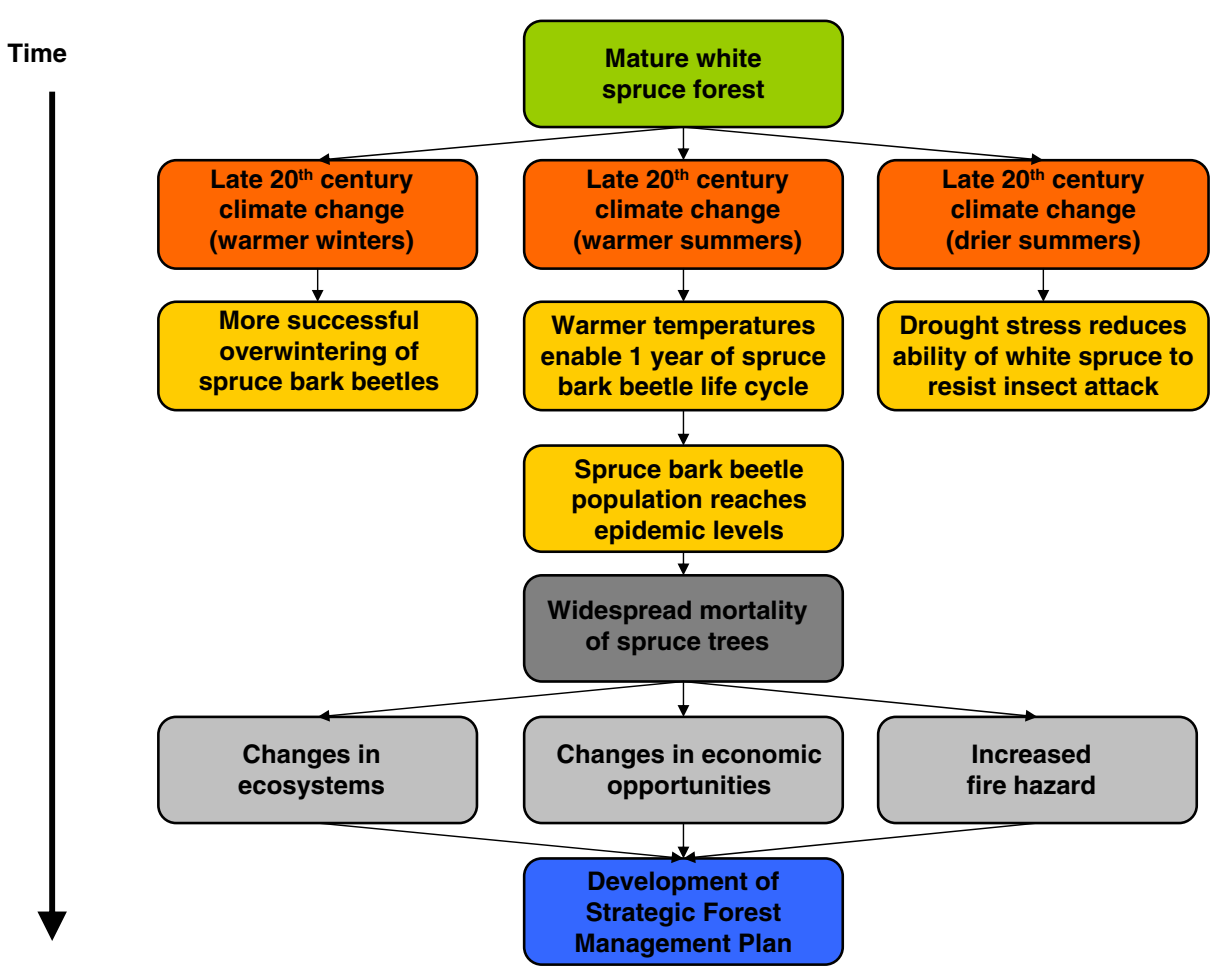

Fig. 2 Events leading to the development of the strategic Forest Management Plan for the Champagne and Aishihik Traditional Territory, southwest Yukon. Source: Ogden 2006 